\title{
Neuromarketing in the making: enactment and reflexive entanglement in an emerging field [last version before submission]
}

In: BioSocieties (2015) 10(4): 400-421. doi: 10.1057/biosoc.2015.37

\author{
Tanja Schneider ${ }^{\mathrm{a}, \mathrm{b},{ }^{*}}$ and Steve Woolgar ${ }^{\mathrm{c}, \mathrm{d}}$ \\ ${ }^{a}$ Institute of Sociology, University of St. Gallen, Tigerbergstr. 2, 9000 St. Gallen, Switzerland, ${ }^{\text {b }}$ \\ Institute for Science Innovation and Society, University of Oxford, Oxford, UK. Email: \\ tanja.schneider@unisg.ch*Corresponding author. \\ 'Tema T, Linköping University, Linköping 58183, Sweden, ' Saïd Business School, University of \\ Oxford, Park End Street, Oxford OX1 1HP, UK. Email: steve.woolgar@sbs.ox.ac.uk
}

\begin{abstract}
:
As the neurosciences make their way beyond the laboratory, they become influential in a wide range of domains. How to understand this process? What are the prospects for, and dynamics of, influence, uptake and rejection? This article reports our attempts to track the emergence of neurosciences with particular reference to the emergence of the field of neuromarketing. Our key initial tasks included the identification and definition of the field, the negotiation of access, and establishing relations with participants and informants. These tasks gave rise to what are often construed as familiar 'methodological difficulties', such as how to define the field and what to make of the reactions and responses of those involved in neuromarketing. In this paper we present some of our experiences of researching the empirical materials of neuromarketing to assess different responses to 'methodological difficulties' in studying science and technologies in the making. We draw on analytic resources provided by Science and Technology Studies (STS) to address the challenge of studying emerging fields of science, practices and technologies. In particular, we draw on the concepts of multiplicity, performativity and practical ontology (Mol, 2002; Law, 2004; Jensen, 2010) to argue that a particular approach to 'methodological difficulties' can actually enrich our research objectives. We suggest that reflexivity be understood, not predominantly as a methodological corrective to the problems of detecting an antecedent object of research; but as revealing some of the ways in which neuromarketing is enacted.
\end{abstract}




\section{Introduction}

The initial impetus for this paper was our growing unease and inability succinctly to answer the question: 'What is neuromarketing?'. We started with the simple idea that neuromarketing is the application of neuroscience to marketing, but quickly came to understand that neuromarketing can mean different things at different times and to different people. Much like anthropologist Michael Moerman's (1965) inability to 'find the Lue' in his fieldwork in Thailand, we found it difficult to find a set of neuromarketers, who would agree on a definition of neuromarketing or who used the same (combination of) technologies, even though they considered themselves to be working 'in the field' of neuromarketing. We also found that 'what neuromarketing is' is a matter to be deferred, that is, participants provided a range of views about where 'real' neuromarketing was going on, who were the experts on this question, and how and when neuromarketing might change. Things became even more complicated when online press coverage announced our own involvement in the field: a team based at the University of Oxford is to conduct a "Study to look at the uses and impact of neuromarketing" (Bain, 2011). An unexpectedly large response to this announcement, by a variety of constituencies 'in' and 'beyond' neuromarketing, effectively turned us into a further node in the very network which we set out to study.

In this paper we document our efforts to make sense of neuromarketing by taking the variability of interpretation and multiplicity of activities among neuromarketing actors as our starting point (Jensen, 2010: 19). Drawing on our fieldwork to date, we report the enactment of neuromarketing in multiple situations and networks and discuss the consequences. As part of this, we consider our own 'performative' entanglement in defining and enacting neuromarketing, and we problematise the supposed benefits of maintaining 
ethnographic distance. We pursue the sense and implications of the suggestion that our problem in answering 'what is neuromarketing?' has to do with its "seemingly paradoxical ontology" as a multiple object (see also Jensen, 2010: 21, on the electronic patient record). By this we mean that neuromarketing is enacted differently by different actors in diverse practices and spaces (cf. Mol, 2002). This seems to pose a paradox in the sense that the technology under study is neither coherent nor consistent (Jensen, 2010: 21). But we suggest that a description of our attempts to confront and manage this 'seeming paradoxical ontology' itself provides a useful resource for revealing key features of the social dynamics of neuromarketing.

Based on our fieldwork encounters, this paper aims both to draw on and contribute to themes in Science and Technology Studies (STS) and related fields that highlight the researchers' entanglements with objects and actors they study and follow. In other words, we consider the enactive or performative ${ }^{1}$ capacities of our own research practices and theoretical commitments, and how these contribute to the enactment of the realities we set out to understand. At the same time we pay attention to how neuromarketing performs us. This acknowledgement of the ontological politics (Mol, 2002) involved in researching neuromarketing raises new questions. Most notably the question of how to manage our (perhaps inevitable) potential for enacting the very realities that we set out to describe, discover and/or deconstruct. Law and others have brought attention to these issues by asking researchers to consider which realities they want to help bring into being (e.g., Law and Urry, 2004) and what kind of methods this would require (e.g., Law, 2004). Relatedly, Law (2009) recommends a 'strategy of interference' and Jensen (2010) proposes that descriptions be understood as interventions ${ }^{2}$. What then are the implications for the status of our descriptions of neuromarketing, if we acknowledge our own involvement in the 
ontological work (with other actors) of enacting neuromarketing? How does our entanglement with actors and arguments in our ethnographic encounters with neuromarketing affect us and our agency as STS researchers? We address these questions first by considering our initial efforts to define the field of neuromarketing, and delineating three main responses to the 'problem' of defining the object of study.

\section{What is neuromarketing? It is contested!}

Spurred by both newspaper and academic articles that highlighted the innovative use of medical equipment such as functional magnetic resonance imaging ( $f M R I)$ scanners for the study of consumer behaviour, and proclaimed the advantages of this neuroscientific approach over traditional techniques (e.g. questionnaire, focus group), we embarked on a study of a new form of market research. We set ourselves a first task to gain an overview of what exactly neuromarketing entailed: what are the range of technologies used in neuromarketing research, where and how is it conducted, which researchers and marketers offer these services, which companies employ neuromarketers and how much does a neuromarketing study cost?

Our initial literature review indicated that the term neuromarketing was first coined by Professor Ale Smidts, Professor of Marketing Research at Erasmus University in Rotterdam, in 2002 to describe efforts by marketing academics to consider the use of neuroscientific methods such as $\mathrm{fMRI}$ and EEG for evaluating consumer's responses to marketing stimuli in the laboratory (Lewis and Brigder, 2005). However, the use of fMRI for marketing purposes was reported by Harvard Business School professor Gerald Zaltman in the late 1990s, albeit without mention of the term 'neuromarketing' (Addison, 2005 as cited in Lewis and Bridger, 2005: 36). In addition, our review of neuromarketing consultancy 
websites revealed that others claim to have used neuroimaging since the late 1990s to understand consumers' sub-conscious responses to brands and products (e.g., Neurosense, a British neuromarketing consultancy) ${ }^{3}$.

Academic, professional and commercial interest in neuromarketing has continued to grow over the last decade (Lee et al, 2007; Plassmann et al, 2012). This is reflected in the increasing institutionalization of neuromarketing through, for instance, the establishment of both academic and industry associations (e.g., Association for NeuroPsychoEconomics; Neuromarketing Science and Business Association (NMSBA), the increase of publications in the area (see Plassmann et al, 2012: 18-19), the emergence of new journals or magazines dedicated to neuromarketing research (e.g., Journal of Neuroscience, Psychology, and Economics; Neuromarketing Theory and Practice), the setting up of blogs reporting neuromarketing research news ${ }^{4}$, the growth of neuromarketing consultancies (see Plassmann et al, 2012: 18-19), the uptake of neuromarketing in established, global market research companies (for instance, global market research company Nielsen's acquisition of neuromarketing consultancy Innerscope Research in May 2015, resulting in the launch of a new division called Nielsen Consumer Neuroscience) and the introduction of neuromarketing courses and electives in business school curricula ${ }^{5}$.

The growth of neuromarketing has been accompanied by sceptical responses from neuroscientists, consumer advocates and marketing researchers (Editorial, 2004; Oullier, 2012). Press coverage on the topic of neuromarketing tended to foreground ethical issues arising from this new type of consumer and market research (e.g., Carr, 2008). In the print media much attention focused on the publication of Lindstrom's (2008) book - Buy-ology. How everything we believe about why we buy is wrong. The book described how consumers' brains can be studied for marketing research purposes and was targeted at marketing 
professionals and an interested general public. Media interest focused on the size of the neuromarketing study on which Lindstrom reported (involving 2,081 volunteers from five countries), the public relevance of the topic under study (e.g. the effect of product warning labels on cigarette packs) and the results that were presented as a surprising contrast with previous research (product warning labels make smokers want to smoke more rather than less) (e.g., Miley, 2008).

The potential for public controversy led a number of marketing academics to propose a distinction between academic and commercial dimensions of neuromarketing. For example, Hubert and Kenning suggest a distinction between "[t]he term "consumer neuroscience" [which] comprises the scientific proceeding of this research approach, and "neuromarketing" [which] designates the application of the findings from consumer neuroscience within the scope of managerial practice" (Hubert and Kenning, 2008: 274; Plassmann et al, 2012).

Other responses to this rapid growth included attempts to standardise and regulate neuromarketing practice. A White Paper published by the European Society for Opinion and Marketing Research (ESOMAR, 2011) set out 36 questions and answers “... which will help buyers ensure they are using the correct neuroscience tool for their research purpose while helping providers of neuroscience tools meet the needs of their clients" (ESOMAR, 2011: 3). Another published by the Advertising Research Foundation (ARF) aimed "to help the industry learn how best to apply the capabilities of neuromarketing to real marketing issues and decisions" (2011: 4). Both White Papers acknowledge that while their members (marketing research organisations and advertising companies) are excited and interested in the use of neuroscience technologies for the purpose of market and advertising research, the complexity of the underlying science makes it difficult to assess their validity and decide 
which approach is best for their research purposes. Yet another response was to set up the Neuromarketing Science and Business Association (NMSBA) - a trade association - which proposed neuroethics guidelines for its members (a diverse group of academics and professional neuromarketers).

Based on this literature review and our initial conversations with academic neuromarketing researchers we began our research with an initial definition of neuromarketing, namely 'the use of brain imaging and measurement techniques to understand consumer preferences' (see in particular Senior and Lee, 2008). But our subsequent research experiences make us hesitate to define neuromarketing as a practice straightforwardly bounded by a set of neuroscientific technologies. The remainder of the paper sets out how we arrived at this conclusion. We report our experiences in the field as a narrative of our entanglement with various actors and arguments. We suggest that despite burgeoning research and interest in social studies in neuroscience (see, for instance, Maasen and Sutter, 2007; Ortega and Vidal, 2011; Pickersgill and van Keulen, 2011; Choudhury and Slaby, 2012; Abi-Rached and Rose, 2013), few accounts examine in detail researchers' own experiences of engaging with emerging neurodisciplines or neuropractices (but, see: Cohn, 2008), or, of collaborating in transdisciplinary projects (but, see: Fitzgerald et al, 2014; Fitzgerald and Callard, 2015). We argue that a reflexive account of neuromarketing in the making provides important insights into processes of enactment and entanglement in an emerging field. As we discuss, such an account allows us to analyse how our description of neuromarketing changed based on our research experience, how we performed neuromarketing in our ethnographic encounters, and how in turn we were performed by neuromarketing. 


\section{Researching neuromarketing in the making}

How to study neuromarketing in the making? In our research we consider the emergence and development of neuromarketing through 1) a critical, historical assessment of the role of different market research technologies, using textual analysis and 2) multi-sited ethnographic research and interview study in different locations (e.g., research lab, neuromarketing consultancy) involved in neuromarketing. Our historical and textual analysis examines how different market research technologies have contributed to different conceptualisations of the consumer and consumer behaviour over time. The aim is to compare the consumer conceptualisations over time and to reflect on the intertwined relationship of consumer conceptualisations and market research technologies (e.g., Osborne and Rose, 1999; Lezaun, 2007). Our multi-sited ethnographic research and interview study aims to explore the role of neuroscientific knowledge and brain imaging in the production of authoritative knowledge about the consumer.

The ethnographic approach enables us to gain a detailed, in-depth picture of the neuromarketing research and dissemination. In this article we draw mainly on our ethnographic fieldwork and interviews. More precisely we focus on our initial meetings with self-proclaimed neuromarketers to negotiate access to neuromarketing consultancies and laboratories, some of which were successful and some of which were not. We also report on participant observation undertaken at a key neuromarketing conference in Europe. We recorded these initial encounters in our field notes. Our sampling of organisations to study, and of key events and conferences to attend, was informed by a purposeful sampling strategy: we selected individuals and settings for study on the basis that they might inform 
our understanding of what neuromarketing is and how neuromarketing is done in practice (Creswell, 2007: 125-129).

The multidisciplinary field of Science and Technology Studies (STS) offers a range of analytical resources for studying emerging fields of practices and technologies. In this paper we draw in particular on the concepts of multiplicity, performativity and practical ontology ${ }^{6}$ (Mol, 2002; Jensen, 2010) to consider three key issues that have emerged in our encounters as STS researchers with neuromarketing to date, namely 1) the flexible, unstable and moving boundaries of neuromarketing, 2) the complex relationship(s) between researchers and researched and 3) the issue of 'legitimate knowledge'.

We argue that our field work encounters allow us a) to consider the boundary work involved in the emergence of neuromarketing, b) reflexively to investigate how we as researchers became entangled with the objects, practices and people with study and c) to test how far our descriptions matter, travel and potentially intervene. In addition we suggest that this analytical framework permits us to engage and point to issues in recent discussions in anthropology about collaboration in the sense of considering the actors under study as 'epistemic partners' (Holmes and Marcus, 2008).

Ultimately, we argue in this paper that when studying neuromarketing in the making we are faced with an ontological issue in the sense that:

[a]ctivities such as observing or representing are not seen as distinct from intervening or constructing; rather they are viewed as specific ways of intervening or constructing (e.g. Hacking, 1983). In this view epistemology collapses into ontology and the sciences are reformulated as practical activities aimed at (re-)building the world by adding new elements with new capabilities and new relationships to it. Knowing (and thinking about knowing) is turned into particular styles and methods for connecting and cooperating 
with specific actors (human and otherwise), thus shaping reality or doing practical ontology (Jensen, 2010: 11, emphases in the original)

In this vein, rather than merely studying neuromarketing in the making, our observation and participation involves us in doing and re-doing neuromarketing. From this vantage point the variability of interpretation and multiplicity of activities among the neuromarketing actors is typical of 'messy objects', as has been meticulously portrayed and analysed in Law and Singleton's (2005) study of the management of alcoholic liver disease. Law and Singleton (2005) highlight the difficulty of keeping the condition in focus while studying it. More specifically they found that the accounts they collected differed to such an extent that it was nearly impossible to fit them together. Their attempts to map the trajectories of a patient with alcoholic liver disease thus proved elusive.

Law and Singleton (2005) list four main ways of responding to the conundrum they encountered: a) the technical, b) the managerial, the c) epistemological and the d) ontological. An epistemological strategy acknowledges that

... objects look messy because people have different perspectives on them. [...] Looked at in this way, then, messy objects are interpretatively complex objects, and if we want to understand them we need to take this into account. We need to explain (and in some cases explain away) the different perspectives, and so retrieve the real object behind the interpretations. (Law and Singleton, 2005: 333)

An ontological strategy, on the other hand “... moves us from multiple interpretations of objects [...] to thinking about multiple objects themselves" (2005: 335). To do so involves an understanding of reality as enacted into being - which happens in and through getting to know those realities (2005: 334). 
Law and Singleton's characterisation of the object of study - alcoholic liver disease as dynamic, unpredictable and discontinuous (rather than stable, predictable and continuous) echoes Jensen's (2010) observations when researching the Electronic Patient Record (EPR) in Denmark: EPR proved as elusive as alcoholic liver disease because of its paradoxical ontology. The common assumption that technology is a coherent object and objects are static, homogeneous and consistent proved empirically unworkable. In practice the EPR seemed more like a multiple object "which formed a whole only sometimes, in some places, for some actors and for some purposes" (2010: 21).

In those styles of STS research which might be termed 'amodern' (e.g., Latour, 1993), the idea that objects are static and/or straightforwardly externally available to the researcher, has long been dispensed with. But this nonetheless proves difficult in research practice. In line with Law and Singleton's point that social science methods fail to provide and develop tools for knowing certain objects and realities, Jensen describes his study as developing “... some (anti-) methodological implications of amodern approaches to the study of technological change" with a particular focus on those technical objects that have variable and changing ontologies (2010: 28). In his view, “... such peculiar objects of study require a kind of theoretical and methodological flexibility and attentiveness, which is all too easily diminished if one is certain about how to approach the object because one already knows what it is and does" (2010: 20, emphasis in original) ${ }^{7}$.

So by modifying our initial emphasis on one specific definition of neuromarketing we open ourselves up to a consideration of the nature and currency of alternative suggestions encountered in practice. In this way, the vignettes we present below can be considered initial attempts empirically to "... follow the ontological work which actors put into adding existence to one or another version ..." of neuromarketing (Jensen, 2010: 28). Since this 
ontological work is transformative, it is important to analyse the consequences of these enactments for different practices (e.g. market research) and actors (e.g. consumers, but also for us as researchers of neuromarketing). In doing so we acknowledge that we as researchers also contribute to defining and enacting our research object. In other words, “... one participates with other actors (but of course with different means and aims) in what might be called experiments to articulate and specify the existence of things, and to engage and articulate the consequences of specific reality constructions" (Jensen, 2010: 21). In the next section of the paper we turn to a discussion of selected vignettes of our encounters with different neuromarketings.

\section{To collaborate or to not collaborate?}

One of our first contacts in the field of neuromarketing research confirmed our initial understanding of neuromarketing as an emerging field of consumer and/or market research that relied on the use of brain imaging and measurement technologies to study consumers' preferences. Working both in an academic (UK university) and commercial setting (Brain\&Emotion, a UK based neuromarketing consultancy) our gatekeeper John explained the benefits of using neuroscientific measurement and imaging technologies for identifying what consumers really want. John saw the potential for using neuroimaging technology for understanding consumer behaviour after completing his $\mathrm{PhD}$ in neuroimaging in the late 1990s. Building on his previous work experience as a marketing consultant, he co-founded one of the early neuromarketing consultancies with colleagues who also had academic qualifications in neuroimaging. The co-founders ran and continue to run Brain\&Emotion in parallel to their academic research careers. At the time we met John he had a tenured chair 
position at a public research university in the United Kingdom and contemplated giving up the position in order fully to concentrate on directing Brain\&Emotion.

In our conversations about neuromarketing John stressed the advantages of using more objective neuroscientific data over subjective forms of consumer and market research based on focus groups, questionnaires and interviews. Already familiar with this argument from our literature review, we now witnessed it in action as part of John's sales pitches for his services to potential clients or presented at industry conferences. Yet alongside this often repeated distinction between traditional and neuroscientific methods, we became aware of considerable variability within the set of neuroscientific methods for understanding consumer behaviour. Whereas John continually stressed the advantages of neuroscientific methods over traditional methods in a general way, over time he offered more detailed views on which methods he considered preferable for specific research tasks. Moreover, there seemed to exist an implicit hierarchy of quality of neuroscientific imaging and measurement technologies for marketing purposes - with fMRI scanners reckoned to yield the most accurate measurement of consumers' unconscious reactions to marketing stimuli.

Of course, questions about methods and their appropriate use are common in many academic disciplines. Even if often implicit and unacknowledged, certain methods are considered preferable to others given certain disciplines' traditions and commitments. Nonetheless these methodological issues are interesting to us insofar as they form the ground for much internal debate or boundary work (Gieryn, 1983) in the emerging field of commercial neuromarketing research. John commented on potential clients' lack of understanding about what neuromarketing (and its different methods) can offer. He hoped that an (at that time) impending review of neuromarketing methods by the Advertising 
Research Foundation (2011) might alleviate matters; this review was intended to provide a definitive guide to what neuromarketing research can offer. In addition he indicated that efforts to set up an industry association by a number of neuromarketing companies might assist with communicating neuromarketers' services ${ }^{8}$.

John subsequently qualified these hopes in an informal conversation with Tanja: "As long as companies like NeuroFocus continue to represent neuromarketing in the way they do, they are doing a great disservice to the whole neuromarketing industry" (fieldnotes 04/2010). John was referring to a video clip produced by the neuromarketing consultancy NeuroFocus, acquired in 2011 by Nielsen, one of the largest market research companies in the world. The video clip advertises the neuromarketing research/consulting services of Neurofocus in a format somewhat akin to a pop music video ${ }^{9}$. John described it as some sort of rap music clip that advertised NeuroFocus' ability to 'listen to the brain'. In his view this was a vastly overstated claim that made false promises in an unprofessional way.

Another notable feature of our preliminary encounters with neuromarketing, was John's interest in collaborating with us. Beyond providing access to his company and related field sites, he actively sought to write and publish academic articles with us. John explained to Tanja that the neuromarketing consultancy he co-directs had a firm grounding in the neuroscience side of things but would benefit from additional expertise on the marketing side. Although his neuromarketing consultancy had a strong record in neuroscience research (all partners held academic appointments at highly regarded British universities, as did many of the staff working for the consultancy) it would benefit from greater knowledge of and access to marketing/market and consumer research. Tanja's entry in her fieldnotes states (perhaps with hindsight a little too dramatically): "It looks like the 'marketing' in neuromarketing is missing" (fieldnotes 06/2010). 
From our conversations with John we gathered that the consultancy had tried to fill the gap in their marketing research knowledge by approaching a number of different individuals and organisations. Among other things, John had a) approached a leading, international market research company and pitched to be their neuromarketing partner, $b$ ) attempted to establish a cooperation/regular exchange with a marketing consultancy that had recently become interested in adding neuromarketing to their portfolio and c) met up with marketing professionals and researchers expressing an interest in his companies' work. None of these attempts had resulted in a stable collaboration (or employment of a marketing research expert) except for ad-hoc advice or friendly referrals. He, nonetheless, felt all these efforts had contributed to growing the company's network and reputation.

Around that time we entered the scene to ask for access to conduct an ethnographic study on 'neuromarketing in the making' with a special interest in how neuromarketing insights were taken up by potential clients. With hindsight we see how we could have given the impression that we had insights to offer into how knowledge exchange between different sites could be leveraged to the benefit of the neuromarketing consultancy. Our declared affiliation as researchers in a Business School, Tanja's PhD officially obtained in the discipline of Marketing and Steve, the research project's Principal Investigator's (PI), title as Chair of Marketing in that Business School most likely reinforced that impression.

How did our collaboration with Brain\&Emotion ensue? After three initial meetings (one of them at their main imaging site with other members of their management team) John asked Tanja to help out with literature research on marketing and market research topics, relevant to current projects. Tanja did most of this work remotely from her university office desk, accessing the university's library databases on marketing and market related topics. After this initial research work, she was invited to join John for a presentation of 
Brain\&Emotion's services to a major consumer goods company. John asked Tanja how he should improve his future presentations, given her alleged marketing knowledge. He was particularly interested to know if there was specific marketing terminology or references to key marketing literature which he could include. Tanja offered to comment on the presentation, if John would email the slides to her. However John did not follow up on this invitation.

As part of this post-presentation discussion John also suggested co-authoring "a couple of academic articles targeted at top marketing journals". He said: "We have all this data that is all analysed and only needs to be written up" (fieldnotes 06/2010). John also suggested that these articles might be beneficial for Tanja's academic career - being a postdoc likely to need publications in top journals. He also acknowledged that these publications would be beneficial to Brain\&Emotion and that especially the Oxford affiliation would look good and could increase credibility among peers and future clients. During the conversation Tanja was careful to point out that Steve and she had limited experience in publishing in peer-reviewed Marketing journals. John nonetheless wanted her to explore his proposition with Steve and get back to him. The proposition of co-authorship became a contentious issue over the next few weeks, involving several attempts at negotiation by phone and email. We offered to co-author a reflexive piece on our collaboration between social science and neuroscience, aimed at a Marketing or STS journal at a later stage in our project. However, John did not take up this proposal.

Our hesitation in agreeing to co-authorship put our fieldwork relationship to the test and led us to reflect on some of our assumptions about our ethnographic approach to studying neuromarketing practices. In our initial meetings with John we had always highlighted that an essential part of our study was to participate and observe 
neuromarketing as it was practiced within John's company. In return for regular access to conduct participant observation we offered assistance with relatively menial tasks such as literature research. Although our offer was taken up, it turned out that 'regular access' was interpreted very specifically. Access was strictly by invitation only. Whereas we had envisioned regular visits to one particular office for two to three days each week, we in fact met irregularly in different settings each time. So although we learned a lot about John, his company, the studies they had done and the issues they face, we felt we were only gaining fleeting glimpses of the 'doing of neuromarketing'. Our relationship with John seemed very business-like in the sense that we felt obliged to offer something in return for the time spent with us. We got the impression that John's and his colleagues' interest in collaborating and co-authoring with us formed part of their own marketing strategies for neuromarketing.

The suggestion to co-publish the results of neuromarketing studies raised several issues and questions: 1) Would we, by co-authoring these papers, be seen as endorsing the benefits of neuromarketing? 2) Would our co-authorship lessen our ability (and our credibility) in providing a reflexive voice in debates about neuromarketing? and 3) Would a joint publishing effort turn us into neuromarketers and thereby jeopardise our professional identity as STS researchers? Our initial ethnographic encounters with Brain\&Emotion thus made it very clear that what counts as 'marketing' of neuromarketing for Brain\&Emotion runs counter to what counts as the 'marketing' of us as STS-researchers. This raised further questions: 1) How useful is our methodological approach and how important is it to maintain ethnographic distance? 2) Does the multi-sitedness of our company's field demand techniques other than ethnography (e.g., shadowing: Czarniawska, 2007; co-presence: Beaulieu, 2010)? 3) What will our description of neuromarketing 'do'; or in other words, what kind of neuromarketing do we want to assist in enacting? 


\section{Blurred boundaries: researching neuromarketing or doing neuromarketing?}

Based on our exploratory fieldwork, we developed a research grant application with European colleagues to conduct further research into the neuro-turn in marketing and other disciplines in Europe. When news came through that we had won a substantial research grant Oxford University's departmental press office asked us to draft a press release. The press release went through several drafts as we exchanged emails with our colleagues in the press office, in part due to our determination to make clear in the release that we were "studying what neuromarketers do and the impact of this new form of market research" and NOT conducting neuromarketing experiments ourselves. Eventually we agreed on the text, entitled How consumers think: The growth of neuromarketing and the measurement of consumers' brain responses to products and services. But to our frustration the press release went live on the Oxford University website with a different title Neuromarketing helps illuminate how we choose what we put in our shopping basket. This latter piece began with the statement that a research team based at the University of Oxford was conducting neuromarketing experiments! After some interventions we managed to have the online title changed to Study to look at the uses and impact of neuromarketing.$^{10}$ By this time, however, several blogs and online magazines had already adopted the original information in their own websites. They simply copied and pasted the press release originally posted on the Oxford University website. ${ }^{11}$

One consequence was that we felt we had to do considerable subsequent repair work. For example in a subsequent interview with an online market research magazine reporting the latest news on market research, which resulted in some coverage of our research $^{12}$, Steve spent a significant amount of time spelling out that we weren't actually 
ourselves involved in conducting neuromarketing experiments but instead wanted to study neuromarketers and neuromarketing from the perspective of 'anthropologists of science', thereby aiming better to figure out how neuromarketing technologies and practices contribute to new understandings of consumer behaviour.

An unexpectedly large and varied response to the initial announcement and to the online market research magazine interview effectively turned us into a further node in the neuromarketing network which we wanted to study. For instance, several blogs ${ }^{13}$, online discussion groups (e.g. LinkedIn, Xing) and online magazines in the neuromarketing and market research arena mentioned either the press release or the interview. Disappointingly, rather few comments on those articles were left in the blogs or discussion groups. We did however get some direct responses in the form of emails from journalists interested in reporting our intended study, doctoral students and postdocs applying for jobs in our lab, neuromarketers keen to meet and learn more about our research and from companies wishing to sell us various kinds of neuroimaging and neuromeasuring technologies. Suddenly, we were part of the field we had intended studying. For the most part we were perceived to be neuromarketers, ourselves in the business of conducting neuromarketing experiments. So, despite our efforts to resist the label in our initial field encounter, to maintain our ethnographic distance by sidestepping John's proposal to collaborate in publishing neuromarketing research, we found that the boundaries between our home discipline and that of our subject had been blurred. We realised this was advantageous in terms of gaining access, yet we remained uneasy about the prospect of finding ourselves enrolled in the efforts to market neuromarketing. How to manage this dilemma? In the next two sections we describe how our recognition and acceptance of the multiplicity of 
neuromarketing facilitated our entry into the field and opened doors for future conversations.

\section{Understanding multiple meanings of neuromarketing}

Part of our fieldwork involved attending academic and industry conferences on neuromarketing. One of the larger conferences Tanja attended was the NeuroPsychoEconomics conference organised by the Technical University of Munich, School of Management for the NeuroPsychoEconomics Association in June 2011. The Association describes itself as

\footnotetext{
“... strategic partner of the American Psychological Association (APA) and the premier scholarly organization for scientists and professionals in neuroscience, psychology, business, marketing, and economics. Founded in 2005, the Association integrates fields such as neuroeconomics, decision neuroscience, and consumer neuroscience. In 2009, the group organizing the Conference on Neuroeconomics (CoNEcs) joined the Association." (taken from website) ${ }^{14}$
}

The two day conference focused on the theme "Excellence in Neuroeconomics - Striving for Impact in Economics, Management, and Marketing Research" with parallel streams on "Consumer behaviour and neuromarketing", "Organisational behaviour and organizational decision neuroscience" and "Behavioural economics and neuroeconomics" in addition to poster and plenary sessions. ${ }^{15}$ One of our aims in attending events such as this was to learn more about current, as yet unpublished, neuromarketing research. As it turned out the event focused nearly exclusively on academic neuromarketing research; very few market research professionals or potential clients attended the conference. Tanja used the coffee 
and lunch breaks to ask participants about their neuromarketing research, what they thought about the event and their views on professional neuromarketing consultancies and more generally about the future of the field. These were relatively informal conversations in which most people also politely asked about Tanja's neuromarketing research or interest. One participant, Marius Schuster, looked at Tanja's name badge and said, "Hang on, I think I have come across your name before". When Tanja explained her interest in neuromarketing, he said "Yes, I think I have read about your research online". Tanja said that this was quite unlikely as we had only just started our study. "Ah, yes but I have set up a Google Alert with the keyword neuromarketing and I think that's how I have come across your name" (fieldnotes 06/2011). Marius was interested to hear more about our project and our views on the neuromarketing market and so we continued the conversation over lunch. His interest was due partly to his plans to set up an Austrian-based neuromarketing consultancy. He was just in the process of writing a business plan based on his academic background in neuroscience and on more recent experience in management consultancy.

Marius spoke about the different technologies used by neuromarketing consultants and the technologies he intended to use in his own consultancy. Three neuro technologies, namely EEG recordings, fMRI scans and measurement of levels of oxytocin (a hormone said to be a valid indicator of trust and generosity), were key to his technology portfolio. He also planned to use biometric measurements such as pupil dilation measurement further to validate his data. Although we had come across similar views in recent press coverage of neuromarketing, this was still surprising. Could biometric measures really be considered 'neural'? Such techniques had been promoted as 'new' market research technologies in the 1970 s and 80 s, but had relatively quickly been superseded by alternative forms of market research technologies such as the focus group, and had failed to be taken up in mainstream 
marketing research mainstream. Were these now once again part of the marketing mainstream? The proposed use of hormonal measurements was also a surprise, in that this was the first time Tanja had heard that they could be considered part of neuromarketing. Against our initial fixation on fMRI scanners, we were lead to wonder whether and in what sense the field of neuromarketing was actually bounded by any specific neuroimaging and neuromeasurement technologies.

Our conversation with Marius continued after the conference. Tanja had agreed to give feedback, by email and Skype, on his draft business plan. Tanja's comments focused mainly on the marketing terminology used in the business plan, the analysis of potential competitor's and questions about one technology that Marius proposed to use. When he subsequently visited Oxford a few weeks later, Tanja asked him about the specifics of setting up a new neuromarketing consultancy; what where his next steps in establishing the company, what infrastructure and equipment was required, how did he draw on other contacts/experts in the field etc.? One of the key tasks was to collect an EEG-dummy dataset that would be used to develop a 'plug-and-play algorithm'. He said he anticipated spending several weeks on this and would draw on the expertise of colleagues at a university in his hometown where he had also studied for his MSc in Neural and Behavioural Science. It became clear that Marius had established a strong network of neuroscientists as well as consultants on whom he could draw for expertise, advice and equipment. He had also solicited feedback on his business plan from broad range of colleagues, friends and expert in related fields such as entrepreneurs, academics and coaches.

Marius asked about the aims of our study and whom we planned interviewing in the industry. Tanja explained our particular interest in the making of new scientific and professional fields and that neuromarketing was an interesting case study for us. Further 
Tanja said that we were paying specific attention to observing which actors, practices and devices were central in the formation of the field of neuromarketing. As an example she mentioned recent efforts by the Advertising Research Foundation (ARF) that at that time was in the process of proposing standards for neuromarketing and the potential impact this might have on the field. Like John, Marius said he would be interested in the results of our study and offered his help. He offered his expertise as a proof reading neuroscientist, if we ever wanted the neuro-side of our draft writing to be checked. He also suggested we may want to consider co-publishing a paper with him as he had not published in any Marketing journals previously and would be interested in collaborating with us. By now familiar with this suggestion from one of our informants, Tanja thanked him and said that she would discuss the possibility with Steve.

As with John, we found ourselves again faced with the offer of potential coauthorship with one of our informants on the basis of our academic affiliation and our supposed marketing expertise. This time, however, instead of saying no, we decided to keep this option open for further exploration. We started to view co-authorship negotiations as a valuable fieldwork experience, rather than a methodological difficulty to be overcome. We began to think that co-authorship itself could prove insightful and, by offering our own descriptions of the field as part of a published paper, may even provide a potential means of intervening in neuromarketing.

\section{Knowing multiple neuromarketings: Eyes and Co., eye-tracking company, UK}

As already mentioned, Oxford University's online press announcement about our neuromarketing research had generated an unexpectedly large and varied response. One 
response was an email from Lucy, a local entrepreneur. In the email she introduced herself as managing director of an eye-tracking company and "restless technology entrepreneur":

I came across your current neuromarketing project while reading the online market research magazine research-live ${ }^{16}$. This topic seems quite relevant to what Eyes and Co. (the technology company I work at) is up to. I thought there's an off-hand chance we could both benefit from meeting up and making a connection? (ref, email, May 2011)

Why should an eye-tracking company be interested in our research on the neuro-turn in marketing? At that time we thought of eye-tracking as a biometric rather than a neural measurement of engagement (with visual marketing stimuli such as brands, logos, packaging or advertisements). During our meeting we explained to Lucy that we were just about to start on a more detailed study of neuromarketing and would appreciate any thoughts she would be happy to share with us. We asked Lucy about her company, the technologies they use and the market for this kind of services, the validity she accorded to these measurements, clients' responses and her views in general about the field of neuromarketing. We asked her views on the different technologies used and eventually ventured the question as to why she thought of eye-tracking as neuromarketing. Her answer was telling: eye-tracking was not neuromarketing. But it sometimes proved useful (for her and the company) to be associated with the neuromarketing 'banner' (fieldnotes 05/2011). It seemed that neuromarketing provided a new means of advertising/marketing old biometric technologies.

In hindsight the meeting with Lucy as well as the other unexpected responses to the online press coverage turned out to be a crucial point in our initial fieldwork. We had to abandon our own working definition of neuromarketing as a field bounded by a specific set 
of brain-imaging and brain-measurement technologies. Rather we needed to pay much greater attention to the nature and currency of definitions and descriptions produced by self-declared neuromarketers. In line with a familiar dictum of anthropological fieldwork, we realised the importance of gathering the various interpretations and definitions of all the involved actors, and of taking them seriously, rather than as mere deviations from an 'official' definition (see also Jensen, 2010: 24). Our own official definition of the field had been based on our initial review of the trade press literature and academic review articles. Our fieldwork encounters reminded us that descriptions and definitions of neuromarketing are performative. They each enact a particular field site for study, and a particular set of actors and technologies, and in the process foreclose others. In this sense our initial, ethnographically inclined explorations of neuromarketing were pivotal in reminding us that

the ethnographic field cannot simply exist, awaiting discovery. It has to be laboriously constructed, prised apart from all the other possibilities for contextualisation to which its constituent relationships and connections could also be referred. This process of construction is inescapably shaped by the conceptual, professional, financial and relational opportunities and resources accessible to the ethnographer. (Amit, 2000: 6)

We would go further. It is not just 'the field' that is constructed. Nor is it merely 'constructed'. Rather, the very objects and actors 'in' the 'field' are enacted in and through our 'participation' and 'observation, ${ }^{17}$. In the next section we look in more detail at the performativity of our engagements and descriptions. 


\section{Beyond descriptions: neuromarketing collaborations and legitimate knowledge}

By sharing selected vignettes from our on-going research of neuromarketing, we hope to have illustrated some of the diversity of the neuromarketing practices we study. Initially, this caused us carefully to reconsider and reassess our methodological approach. It seemed difficult to achieve a prolonged period of participant observation in the field of neuromarketing due to problems of participation, of time, of space and of invisibility (see also Czarniawska, 2007: 13-16). Moreover, we had learned that we were expected to offer a 'return on investment' in exchange for access as participant observer. This return on investment was measured either in terms of how much our contributions could raise the credibility of the company being studied (as alleged marketing experts and also academics at the University of Oxford) or in terms of the information we could deliver about the work of competitors. The price of access even led us to consider whether an interview study would be better suited to studying neuromarketing. Perhaps interviews would allow us to maintain some distance from our object and yet capture a wide range of views, including those of neuromarketers we did not initially think of as doing neuromarketing.

Various STS debates about the limits of methods, messy and multiple objects and the turn to ontology, as discussed in this paper, speak to this issue. These debates have led, for example, to proposals to deploy method assemblages (Law, 2004) and to use inventive methods that are made specific and relevant to a particular problem (Lury and Wakeford, 2012). Our research on neuromarketing in the making draws on these debates. However, the experience of ourselves being enacted as neuromarketers goes beyond the epistemological issue of 'going native' in 'the field'. In line with recent STS arguments we are instead faced with an ontological issue. Our fieldwork experiences are experiences of 
ontology in practice (cf. Jensen, 2010: 11). Moreover, our encounters as STS researchers and, indeed non-specialists, in the area of neuromarketing, with the various neuromarketers led us reflexively to investigate how we as researchers are entangled with the objects, practices and people we study.

As Fitzgerald and Callard (2015) recently observed this potential entanglement is part and parcel of 'interdisciplinary' collaborations across the social sciences and neurosciences. Based on their own collaborative encounters in this sphere, they suggest that literature on interdisciplinarity between the social sciences and life sciences offers a limited understanding of what these encounters provoke. They propose "... an alternative programme, paying particular attention to the 'experiment' [of interdisciplinary collaboration] as a space of intervention, and using 'entanglement' explicitly to depart from logics of 'engagement' and 'dialogue'" (Fitzgerald and Callard, 2015: 4, our addition). The key difference between Fitzgerald and Callard's account of experimental entanglement and our own entanglement with the object of our study is the terms of collaboration. Fitzgerald and Callard actively sought out collaborations with neuroscientists further to investigate a shared research interest - as in their use of "... neuroimaging to explore the deep and contingent intertwinement of truth, lie, situation, and feeling (Littlefield et al., in preparation; Littlefield et al., 2014; Fitzgerald et al., 2014)" (Fitzgerald and Callard, 2015: 19). We set out to participate in and observe neuromarketing studies in laboratory settings, rather than to collaborate. Nonetheless, we repeatedly encountered invitations to collaborate. We argue that encountering these as unexpected invitations, rather than forging them at the outset of our study, led us to reflect how such invitations raise questions about what might count as co-producing 'legitimate knowledge'. Different versions of legitimate knowledge are performed in our ethnographic encounters. Neuromarketers 
hoped that we could add legitimacy to their practices and assist in marketing neuromarketing. They imagined us sitting on 'knowledge about markets and marketing'.

We suggest that this interrelated issue of collaboration and legitimacy is pertinent beyond our own ethnographic encounters as STS researchers with neuromarketing; it is instead exemplary of the development of neuromarketing as a new practice of market(ing) and consumer research. By this we mean that despite on-going attempts to differentiate between consumer neuroscience and neuromarketing, many academic as well as professional neuromarketers (e.g., consultants, market researchers) work collaboratively across disciplines and academic/professional backgrounds to access and share their 'knowledge' on markets, neuroscience, consumer behaviour, consumer goods, branding and so on.

Examples of these forms of collaboration - themselves constituting a form of marketing networks - include collaborations between neuroscientists and marketing researchers, neuromarketing consultancies keeping close links with universities (either in terms of on-going academic appointments or collaborations with academic colleagues which enable access to scanning equipment), and the appointment of renowned neuroscientists or academic neuromarketing researchers to the advisory board of neuromarketing consultancies $^{18}$. These collaborations involve more than the exchange of knowledge and expertise. Rather these are a crucial means of establishing legitimacy and credibility for neuromarketing practices. Collaborations or multi-disciplinary teams signal qualification to conduct neuromarketing research. Thus, for example, in ESOMAR's 36 Questions to help commission neuroscience research, it is recommended that prospective neuromarketers be asked "how many of staff with the relevant academic qualifications has this company?"; 
"what are their academic qualifications?" and "have they published any relevant papers/articles?" (ESOMAR, 2011: 3, question 2).

Given the interrelated nature of collaboration and legitimacy, often related to efforts and attempts to market neuromarketing, how should we respond as STS researchers? How can we prevent (our) engagements with neuromarketing being turned into a tool for legitimation? Is it in any case always preferable to resist being used in this way? Reflecting on the repeated invitations to co-author academic papers with the neuromarketers, the main reason for our hesitation was that we didn't want to lend our names and affiliations to a study that we had not undertaken ourselves and to which we were only invited to "writeup using the relevant literature and jargon for a Marketing journal" (fieldnotes 06/2010). Such a request would not leave room for our own description of neuromarketing research (but see, for instance, Fitzgerald et al, 2014 for a discussion of a transdisciplinary neuroscience encounter). However, those journals that allow us to offer descriptions of neuromarketing informed by our own disciplinary background are not necessarily read by many neuromarketers. So, how can we make our descriptions intervene?

Based on our own limited experience in the initial stages of our research project we found that our direct contact with neuromarketers (and conversations with journalists) offered most potential for ontological intervention - in both directions. By pointing out the multiplicity of neuromarketing ${ }^{19}$ to neuromarketing practitioners and academics, for instance, we generated discussions which both challenged their accounts and also allowed them to challenge ours. By letting others intervene in what we are trying to do, we also allowed our research participants and informants to redefine our study, in the way we have described in this paper. Our approach then follows Vikkels $\emptyset^{\prime} s$ suggestion - inspired by Stengers - that “... good descriptions are descriptions that are put at risk by being exposed 
to multiple audiences and allowed to become affected by the audiences' reactions" (Vikkels $\varnothing, 2007: 308)$. This leads us to think of those neuromarketers with whom we spoke and/or observed not as 'epistemic partners' (Holmes and Marcus, 2008) but rather as 'ontological interlocutors'. By this we mean that by studying, engaging with and knowing neuromarketing we are doing/enacting neuromarketing. In the process

... many agents constantly negotiate and influence each other, in order to achieve multiple conflicting goals. A picture thus emerges of intervention as mutual betrayal, or, more positively, as a process of artful contamination whereby actors spread their agendas, ideas and aspirations. (Zuiderent-Jerak and Jensen, 2007: 231-232)

\section{Conclusion: or how our descriptions of neuromarketing intervene/d}

We have described some of the initial challenges and ambivalences when embarking on a qualitative field study of neuromarketing, drawing on a sample of ethnographic vignettes and reflexive notes. We have used these to address the question 'how to study neuromarketing in the making', drawing on the concepts of multiplicity, performativity and practical ontology (Mol, 2002; Law, 2004; Jensen, 2010). Following an 'ontological strategy' (Law and Singleton, 2005) in our fieldwork that moves us from multiple interpretations of neuromarketing to considering multiple neuromarketings allows us to highlight how one or another neuromarketing is enacted into being - including our own enactments, and how neuromarketing performs us. We have also discussed the specific challenges raised by our ontological/theoretical commitments (cf. Munk and Abrahamsson, 2012) when trying to deal with questions of collaboration and legitimacy. 
This begs the question, what kind of reality do we help bring into being when describing the field and practices of neuromarketing? In this paper we have reported and reflected upon the kinds of interventions that we made by way of descriptions such as press release, website accounts of our research project, the relations drawn between otherwise disparate people and organisations in practice and in the presentation of the vignettes ${ }^{20}$. But our practical attempts to confront and manage the 'paradoxical ontology' of neuromarketing also brought us to realise how much we had relied upon implicit objectivist assumptions about the antecedent existence of 'the field'. Thus, our concerns about accepting the invitation to co-author, construed as a form of 'intervention', can be understood as a direct reflection of our assumption that 'the field' existed independently of our research actions. Similarly, our early determination to make clear that we were researching neuromarketing, rather than ourselves actually doing neuromarketing, reflects a commitment to the notion of analytic distance between researcher and researched. By becoming more attuned to practical ontology, our somewhat traditional methodological concerns gradually gave way to the possibility of alternative research tactics. We were inundated with inquiries about 'our' neuromarketing research (laboratory): why not set up our own neuromarketing consultancy as a form of breeching experiment, to see how far we could hold up the notion that we are neuromarketers? We were immersed in assumptions about our own expertise in neuromarketing: why not put oneself forward for election as the NMSBA's local chair and country representative? Of course, our experience of being invited as academics to co-author articles, collaborate etc. may reflect collaborative practices which are frequently encountered in neuromarketing practice. As such our study contributes not only to discussions about how to study emerging practices and fields of research but also to 
the discussion about what role and impact the social studies of neuroscience may have when researching the neuro-turn in the social sciences and humanities.

We suggest that providing alternative descriptions online, in academic journals, when interviewed by journalist or when talking to neuromarketers, constitute interventions which enable people to respond differently to issues (Jensen 2010: 15). Such a position is akin to Law's 'strategy of interference' in the sense that any description we offer when accounting for the specificities and uncertainties of the empirical intervenes, “... because its descriptions are always and necessarily performative and so they make a difference" (Law, 2009: 10). We would add that these descriptions are, however, not necessarily only written papers produced during or at the end of our research. They can usefully be thought of as conversations in the field in which we mirror our ongoing sense making to our participants and informants. The 'final' answer to the question of 'what kind of reality do we (want to) help bring into being when describing the field and practices of neuromarketing' might not be entirely in our hands, however, as it is difficult to control the fate of enacted descriptions. Nonetheless, we can study and describe the trajectories of descriptions as another way of learning (more) about the object of our study.

Finally, we wish to draw attention to another kind of intervention achieved by the description provided in this paper. In a superficial reading, we have merely outlined some common concerns and anxieties about our methodology. These are familiar concerns about sources of potential methodological trouble, deriving from a standard commitment to the prior antecedent existence of the object of our study: neuromarketing. We have argued that it is more fruitful to replace this commitment with an appreciation of the ways in which our involvement in the field actively constitutes multiple neuromarketings. Neuromarketing is differentially enacted in and through our research practices and those of our 'informants'. 
Now, in the particular sense of text articulated by Dorothy Smith $(1978 ; 1999,2002)$, we can see that the organisation of our own narrative text provides some insights into what 'makes' neuromarketing. For Smith, the organisation of a text is 'isomorphic with' the concept we use to make sense of it. In other words, the particular way in which the text is organised brings into being the phenomenon which the text is supposedly 'about'. For example, in her analysis of a text which purports to describe someone suffering mental illness, Smith (1978) shows how key organizational features of the account - the depiction of which characters have which attributes, who is responsible for what, which persons ally with the views of others, what counts as behaviour 'out of character' and so on - sustain (enact) the key features of what we think of as mental illness.

By analogy, we suggest that the text we have ourselves assembled, this paper, might be fruitfully analysed for the ways in which its organization enacts key features of how we have come to think of neuromarketing. In particular, this might enable us to notice how different actors are introduced at different stages of the narrative; questions raised about their membership of the field; contrasts established between the appropriateness of different neuro-technologies; motives differentially assigned to, for example, consultants and academics. In a way resonant with more recent STS arguments that practices (in this case, texts) constitute (enact) realities, Smith shows that what the text 'conveys', or apparently 'reports upon', is not so much an antecedent phenomenon as the upshot of particular practices of enactment. By pursuing this kind of analysis of our own narrative account of 'methodological troubles', we hope to be able to reveal more about the structure and attributes of the community of actants, which sustain the particular sense(s) of neuromarketing we have thus far encountered. In other words, our attempts to confront 
Page 34/39

and manage 'paradoxical ontology' constitute a narrative account whose organisational structure encapsulates key features of the social dynamics of neuromarketing. 


\section{References}

Abi-Rached, J. and Rose, N. (2013) Neuro: The New Brain Sciences and the Managment of the Mind. Princeton: Princeton University Press.

Addison, T. (2005) More science: more sense or nonsense. Admap 461: 24-27.

Advertising Research Foundation (ARF) (2011). NeuroStandards Project White Paper. New York: Advertising Research Foundation.

Amit, V. (2000) Introduction: constructing the field. In: AMIT, V. (ed.) Constructing the Field: Ethnographic Fieldwork in the Contemporary World. Abingdon: Routledge.

Bain, R. (2011) Study to look at the uses and impact of neuromarketing. research. http://www.research-live.com/news/study-to-look-at-the-uses-and-impact-ofneuromarketing/4005133.article, accessed 5 May 2011.

Beaulieu, A. (2010) From co-location to co-presence: shifts in the use of ethnography for the study of knowledge. . Social Studies of Science 40(3): 453-470.

Carr, N. (2008) Neuromarketing could make mind reading the ad-man's ultimate tool. The Guardian, April 3.

Choudhury, S. and Slaby, J. (eds.) (2012) Critical Neuroscience: A Handbook of the Social and Cultural Contexts of Neuroscience. Chichester: Wiley-Blackwell.

Cohn, S. (2008) Petty Cash and the Neuroscientific Mapping of Pleasure. BioSocieties 3: 151163.

Creswell, J. W. (2007) Qualitative Inquiry and Research Design: Choosing among Five Approaches. London: Sage.

Czarniawska, B. (2007) Shadowing: And Other Techniques for Doing Fieldwork in Modern Societies. Copenhagen: Copenhagen Business School Press.

Editorial (2004) Brain scam? Nature Neuroscience 7(7): 683.

ESOMAR (2011). 36 Questions to Help Commission Neuroscience Research Amsterdam, NL: ESOMAR.

Fitzgerald, D. and Callard, F. (2015) Social science and neuroscience beyond interdisciplinarity: experimental entanglements. Theory, Culture \& Society 32(1): 332.

Fitzgerald, D., Littlefield, M. M., Knudsen, K. J., Tonks, J. and Dietz, M. J. (2014) Ambivalence, equivocation and the politics of experimental knowledge: A transdisciplinary 
neuroscience encounter. Social Studies of Science 44(5): 701-721.

Gieryn, T. (1983) Boundary work and the demarcation of science from non-science: strains and interests in professional ideologies of scientist. American Sociological Review 48(6): 781-795.

Holmes, D. R. and Marcus, G. E. (2008) Collaboration today and the re-imagination of the classic scene of fieldwork encounter. Collaborative Anthropologies 1: 81-101.

Hubert, M. and Kenning, P. (2008) A current overview of consumer neuroscience. Journal of Consumer Behaviour 7(4-5): 272-292.

Jensen, C. B. (2010) Ontologies for Developing Things: Making Health Care Futures Through Technology. Rotterdam: Sense Publishers.

Jensen, C. B. (2014) Practical Ontologies. Fieldsights - Theorizing the Contemporary. Cultural Anthropology Online, 13 January 2014 http://www.culanth.org/fieldsights/466practical-ontologies, accessed 22 June 2015.

Latour, B. (1993) We have never been modern. Cambridge, MA: Harvard University Press.

Law, J. (2004) After Method: Mess in Social Science Research. London: Routledge.

Law, J. (2009). The Greer-Bush Test: on Politics in STS, version of 23rd December 2009.

Law, J. and Singleton, V. (2005) Object lessons. Organization 12(3): 331-355.

Law, J. and Urry, J. (2004) Enacting the social. Economy and Society 33(3): 390-410.

Lee, N., Broderick, A. J. and Chamberlain, L. (2007) What is 'neuromarketing'? A discussion and agenda for future research. International Journal of Psychophysiology; Special Edition: Cognitive Neuroscience: Contributions from Psychophysiology 63(2): 199204.

Lewis, D. and Brigder, D. (2005) Market Researchers make Increasing use of Brain Imaging. Advances in Clinical Neuroscience and Rehabilitation 5(3): 36-37.

Lezaun, J. (2007) A market of opinions: the political epistemology of focus groups. The Sociological Review 55(2): 130-151.

Lindstrom, M. (2008) Buy-ology. How Everything We Believe About Why We Buy is Wrong. London: Random House Business Books.

Lury, C. and Wakeford, N. (eds.) (2012) Inventive Methods: The Happening of the Social. Abingdon, Oxon: Routledge.

Maasen, S. and Sutter, B. (eds.) (2007) On Willing Selves: Neoliberal Politics vis-à-vis the Neuroscientific Challenge. Basingstoke: Palgrave Macmillan.

Miley, M. (2008) Anti-Smoking warnings make you want to smoke, claims study. Ad Age. 
http://adage.com/article/news/anti-smoking-warnings-make-smoke-claimsstudy/131905/, accessed 13 March 2015.

Moerman, M. (1965) Ethnic identification in a complex civilization: who are the Lue? American Anthropologist 67(5): 1215-1230.

Mol, A. (2002) The Body Multiple: Ontology in Medical Practice. Durham: Duke University Press.

Munk, A. K. and Abrahamsson, S. (2012) Empiricist interventions: strategies and tactics on the ontopolitical battlefield. Science Studies 25(1): 52-70.

Ortega, F. and Vidal, F. (eds.) (2011) Neurocultures: Glimpses into an Expanding Universe. Frankfurt am Main: Peter Lang.

Osborne, T. and Rose, N. (1999) Do the social sciences create phenomena? The example of public opinion research. British Journal of Sociology 50(3): 367-396.

Oullier, O. (2012) Clear up this fuzzy thinking on brain scans. Nature 483(7387): 7.

Pickersgill, M. and van Keulen, I. (eds.) (2011) Sociological Reflections on the Neuroscience. Bingley, UK: Emerald Group Publishing.

Plassmann, H., Zoëga Rams $\varnothing$ y, T. and Milosavljevic, M. (2012) Branding the brain: A critical review and outlook. Journal of Consumer Psychology (Special Issue on Brand Insights from Psychological and Neurophysiological Perspectives) 22(1): 18-36.

Schneider, T. and Woolgar, S. (2012) Technologies of ironic revelation: enacting consumers in neuromarkets. Consumption, Markets \& Culture 15(2): 169-189.

Senior, C. and Lee, N. (2008) A manifesto for neuromarketing science. Journal of Consumer Behaviour 7(4-5): 263-271.

Smith, D. (1978) K is mentally ill: the anatomy of a factual account. Sociology 12: 23-53.

Smith, D. (1999) Writing the social: critique, theory and investigations. Toronto: University of Toronto Press.

Smith, D. (2002) Texts, Facts and Femininity: Exploring the Relations of Ruling. London: Routledge.

Vikkels $\varnothing$, S. (2007) Description as intervention: engagement and resistance in actor-network analyses. Science as Culture 16(3): 297-3-9.

Woolgar, S. and Lezaun, J. (2013) The wrong bin bag: a turn to ontology in science and technology studies? Social Studies of Science 43(3): 321-340.

Woolgar, S. and Lezaun, J. (2015) Missing the (question) mark: What is the turn to ontology? Social Studies of Science 45(3): 462-467. 
Woolgar, S. and Neyland, D. (2013) Mundane Governance: Ontology and Accountability. Oxford: Oxford University Press.

Zuiderent-Jerak, T. (forthcoming) Situated Intervention. Cambridge, MA: MIT Press.

Zuiderent-Jerak, T. and Jensen, C. B. (2007) Editorial introduction: Unpacking 'intervention' in science and technology studies. Science as Culture 16(3): 227-235.

\section{Endnotes}

\footnotetext{
${ }^{1}$ Among the wide variety of terms denoting processes whereby 'realities' are brought into being, we prefer 'enactment' and 'performance', in line with a heightened attention to ontological rather than merely epistemological constitution (see Woolgar and Lezaun, 2013; Woolgar and Neyland, 2013). For purposes of this paper we use the terms interchangeably (but see Mol, 2002).

${ }^{2}$ It remains rather unclear what practical actions are connoted by terms like 'interference' and 'intervention' (see Woolgar and Lezaun, 2013; Zuiderent-Jerak, forthcoming).

${ }^{3}$ Available at: http://www.neurosense.com/aboutus/ [accessed 16.6.2015].

${ }^{4}$ Examples include, http://www.neurosciencemarketing.com/blog/ and http://neurorelay.com [both accessed 16.6.2015].

${ }^{5}$ The Rotterdam School of Management, Erasmus University (NL) offers a neuromarketing elective as part of their Master of Science in Marketing Management. Professor Thomas Zoëga Rams $\varnothing y$, Head of the Center for Decision Neuroscience, Department of Marketing at Copenhagen Business School (DK), offers a free online course entitled An Introduction to Consumer Neuroscience \& Neuromarketing via the online education platform Coursera.

${ }^{6}$ Jensen describes any mode and method for knowing as ontological rather than epistemological as they are 'shaping reality' (2010: 11). This includes ethnography which "... can itself be conceived as an ontological form. The kinds of topics we like to talk about as epistemological thus collapse into ontology, and fieldwork, writing, and argumentation begins to look like small machines for intervening in this or that part of the world, for performing the world in this or that marginally different or novel way (Jensen 2012)." (Jensen, 2014).

${ }^{7}$ It is unclear why this characterisation should apply only to a certain sub set ("such peculiar objects") of all objects.

${ }^{8}$ In the meantime the industry association that John referred to has been founded and launched in January 2012 under the name Neuromarketing Science and Business Association (NMSBA). For more information: http://www.nmsba.com [accessed 16.6.2015]

${ }^{9}$ The video clip as well as the lyrics are available to view on Youtube:

https://www.youtube.com/watch?v=M27e7i0VMBg [accessed 13.3.2015].

${ }^{10}$ http://www.ox.ac.uk/media/news_stories/2011/110605_1.html [accessed 08.2.2012].

Unfortunately the link is no longer working.

${ }^{11}$ For instance, see http://www.sciencedaily.com/releases/2011/05/110510155852.htm [accessed 16.06.2015].

${ }^{12}$ Available at: http://www.research-live.com/news/study-to-look-at-the-uses-and-impactofneuromarketing/4005133.article [accessed 16.06.2015].
} 
${ }^{13}$ For instance, see: http://www.neurosciencemarketing.com/blog/articles/oxfordneuromarketing.htm [accessed 16.6.2015].

${ }^{14}$ Available at: http://www.jnpe.org/front_content.php [accessed 13.03.2015].

${ }^{15}$ For conference programme and proceedings, see: http://www.jnpe.org/upload/pdf/2011_NeuroPsychoEconomics_Conference_Proceedings.pdf [accessed 16.1.2012].

${ }^{16}$ See endnote 14 for a link to the article Lucy referred to.

${ }^{17}$ On the difference between construction and enactment see Woolgar and Lezaun (2015).

${ }^{18}$ For example Eric Kandel, neuroscientist and Nobel prize winner, was a member of the advisory board of NeuroFocus before Neurofocus was bought by the global market research company Nielsen in 2011.

${ }^{19}$ Although not by using words like 'multiplicity'!

${ }^{20}$ In addition, we have used provocation in one of our published papers (Schneider and Woolgar, 2012).

\section{Acknowledgements:}

We would like to thank the individuals and organizations who generously shared their time, experience and materials for the purposes of our research project. An early version of this paper was presented at the "Performing ANT: socio-material practices of organizing"-workshop at the University of St. Gallen, Switzerland. Subsequent versions of our paper were presented at a "Horizon Human Behaviour" seminar, University of Nottingham, United Kingdom, and as part of the "Public Sphere, Crowd Sentiments and the Brain" - public lecture series at the Copenhagen Business School, Denmark. Thanks to the organisers and participants at these events for their valuable observations and suggestions. Thanks also to the editors of BioSocieties and three anonymous reviewers for unusually constructive feedback and suggestions. We especially benefitted from a close reading of our argument by Jonna Brenninkmeijer. Finally, we acknowledge the Economic and Social Research Council (ESRC) for their support of this study through an Open Research Area (ORA) grant (RES-36025-0018). 